\title{
Perceived Marketplace Influence and Sustainable Consumption: Does What We Do Matter?
}

\author{
R. Bret Leary and Richard J. Vann
}

\begin{abstract}
In light of negative environmental trends (US Environmental Protection Agency 2014; Global Footprint Network 2014), it is apparent that smarter consumption by the collective of society is necessary, as it is only in the aggregate that the negative effects of harmful consumption patterns can be lessened and a more sustainable future achieved (Stern 2000; Peattie 2010). However, in interdependent fashion, the ability of the collective to have a positive impact on these environmental issues is a direct result of an individual's inclination to engage in environmentally and socially responsible behavior.

In an effort to capture this unique relationship between the individual, collective, and environmental issues, Leary and colleagues (2014) developed the concept of Perceived Marketplace Influence (PMI) to suggest that when one believes their environmentally responsible behavior holds sway over the actions of other marketplace actors (i.e., other consumers and organizations), they are likely to start or continue engaging in such behavior. Building on the work of these authors, the purpose of the current research is to further explore the concept of PMI, develop and validate a scale for the construct, and test its ability to predict various sets of environmentally responsible behavior. We present the results of three studies in support of these objectives, delivering a scale for PMI and showing its ability to influence environmental and broader sets of ethical behavior. We conclude with a discussion of the implications for marketing, consumer behavior, and policy.
\end{abstract}

\section{References available upon request.}

R.B. Leary $(\bowtie) \bullet$ R.J. Vann

University of Wyoming, Laramie, WY 82071, USA

e-mail: rleary@uwyo.edu; rvann@uwyo.edu 